\title{
The stimulation of pyruvate appearance in the rabbit oviduct lumen by sodium propionate
}

\author{
H. J. Leese \\ Department of Biology, University of York, York YO1 5DD, U.K.
}

\begin{abstract}
Summary. Sodium propionate stimulated the appearance of pyruvate in saline medium recirculated through the lumen of the rabbit oviduct for $4 \mathrm{~h}$ in vivo. The propionate was equally effective whether added to the lumen or infused into the bloodstream. The final pyruvate concentration in the lumen in the presence of propionate was 1.3 times that in the plasma. Propionate increased the pyruvate content of oviduct tissue slices incubated in vitro, indicating that a proportion of the propionate-stimulated pyruvate appearance could be due to the metabolic conversion of propionate into pyruvate.
\end{abstract}

\section{Introduction}

Pyruvic acid is a component of oviductal fluid in a number of species (Brackett \& Mastroianni, 1974) and is probably essential to the survival of unfertilized ova and preimplantation embryos up to the 8-cell stage (Biggers \& Stern, 1973). The movement of pyruvate into saline medium recirculated for $4 \mathrm{~h}$ through the lumen of the rabbit oviduct in vivo has been studied by Leese $\&$ Aldridge (1979). The same technique has now been used to examine the effect of compounds which might interact with this pyruvate transport process.

\section{Materials and Methods}

The perfusion experiments were carried out as described by Leese \& Aldridge (1979). The oviducts of anaesthetized rabbits were cannulated at their uterine and fimbriated ends and $2 \mathrm{ml}$ $0.9 \%(\mathrm{w} / \mathrm{v}) \mathrm{NaCl}$ containing penicillin and streptomycin were recirculated through the lumen at a rate of $50 \mu \mathrm{l} / \mathrm{min}$ for $4 \mathrm{~h}$. Serial samples $(50 \mu \mathrm{l})$ of medium were deproteinized with $6 \%(\mathrm{w} / \mathrm{v})$ $\mathrm{HClO}_{4}$, neutralized with $30 \%(\mathrm{w} / \mathrm{v}) \mathrm{K}_{2} \mathrm{CO}_{3}$ and their pyruvate (and sometimes lactate) content measured by a modification (Leese \& Aldridge, 1979) of the automated fluorometric method of Leese \& Bronk (1972). In some experiments, the femoral vein was cannulated to allow substances to be infused. Tissue slices of rabbit oviduct were prepared as follows. The animals were killed by a blow on the head, followed by cervical dislocation, and the oviduct and surrounding adipose tissue rapidly removed and placed in ice-cold $0.9 \%(\mathrm{w} / \mathrm{v}) \mathrm{NaCl}$. The ampulla and isthmus were dissected from the adhering fat and slit open along their lengths to expose the endosalpinx. The resulting flat sheets of tissue were cut into small (approximately $5 \mathrm{mg}$ fresh wt) pieces, 5 or 6 of which were incubated according to the method of Bronk \& Parsons (1965) in $2.5 \mathrm{ml}$ Krebs-Ringer bicarbonate medium continuously gassed with $95 \%$ $\mathrm{O}_{2} / 5 \% \mathrm{CO}_{2}$. Measurement of oxygen uptake and adenine nucleotide content have shown that such oviduct tissue slices are viable for at least $30 \mathrm{~min}$ (H. J. Leese \& K. S. Jeffries unpublished). After $8 \mathrm{~min}$, the tissues were removed, blotted to remove adhering medium, added to $0.5 \mathrm{ml}$ 
ice-cold $6 \%(\mathrm{w} / \mathrm{v}) \mathrm{HClO}_{4}$ and extracted for $1 \mathrm{~h}$. The tissue was removed, blotted and weighed, and the results are expressed in terms of this post-extraction weight. Slices of unincubated tissue were deproteinized and weighed in a similar manner. The $\mathrm{HClO}_{4}$ extracts were neutralized and assayed for pyruvate as described above. a-Cyano-4-hydroxycinnamate an inhibitor of pyruvate transport in liver mitochondria and human erythrocytes (Halestrap \& Denton, 1974), was obtained from the Aldrich Chemical Company, Milwaukee, Wisconsin, U.S.A.

\section{Results}

After a control period of $2 \mathrm{~h}$, different compounds were added to the fluid perfusing the oviducts to see whether they could influence pyruvate and lactate appearance. Sodium pyruvate and sodium lactate at concentrations of $100 \mathrm{~mm}$ failed to influence each other's output significantly, and sodium acetate and sodium butyrate, at $10 \mathrm{~mm}$, were also without significant effect. However, $10 \mathrm{~mm}$-sodium propionate had a dramatic effect on pyruvate appearance, as shown in Text-fig. 1(a) and a small effect on lactate appearance, as shown in Text-fig. 1(b). The rate of pyruvate output was over 4 times greater after the addition of propionate than in its absence.

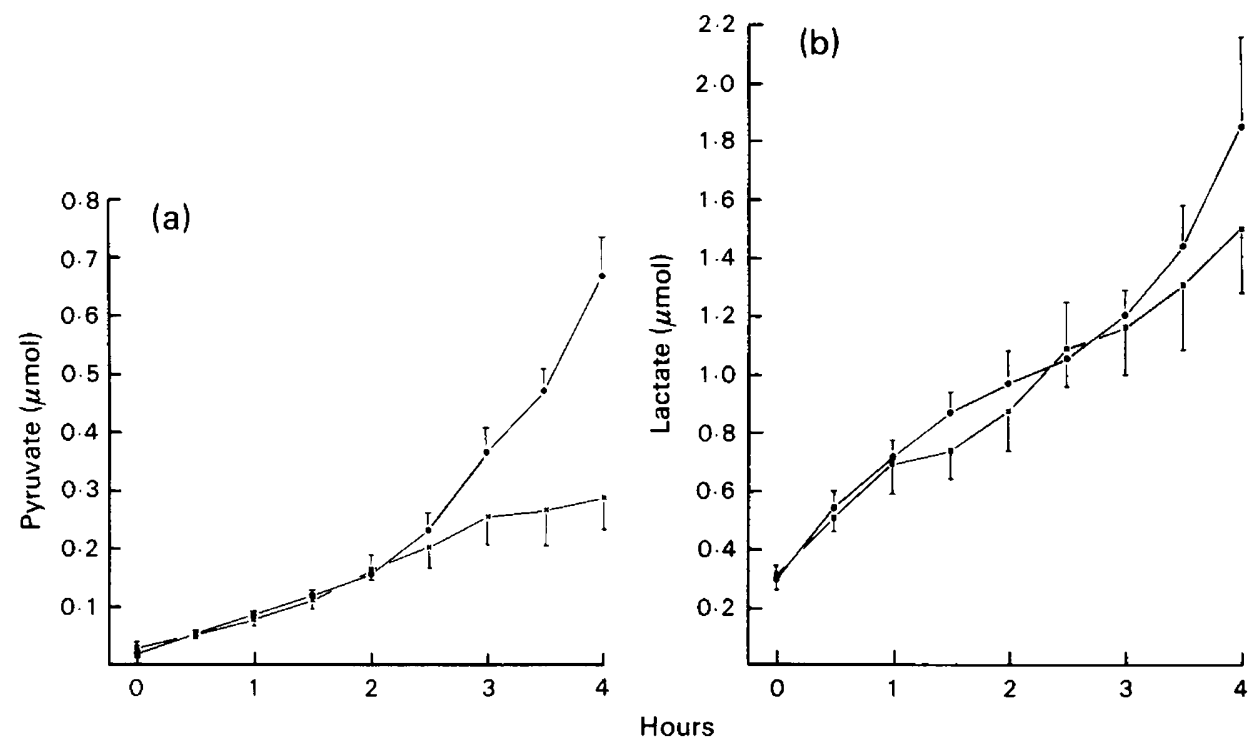

Text-fig. 1. The time course of appearance of (a) pyruvate and (b) lactate in fluid circulating through the rabbit oviduct in vivo. Sodium propionate to a concentration of $10 \mathrm{~mm}$ was added after $2 \mathrm{~h}$. Values are mean \pm s.e.m. for (a) 7 and (b) 6 oviducts. The control data ( $x$ ) are taken from Text-fig. 1 in Leese \& Aldridge (1979).

In control experiments (see Text-fig. 1(a) in Leese \& Aldridge, 1979) the $4 \mathrm{~h}$ pyruvate concentration in the perfusion fluid was $0.16 \pm 0.03 \mathrm{mM}$, and that in the plasma $0.61 \pm 0.17$ $\mathrm{mM}$, i.e. a ratio of 0.26 . After the addition of propionate, the final pyruvate concentration in the perfusion fluid was $0.37 \pm 0.04 \mathrm{~mm}$ and that in the plasma $0.29 \pm 0.06 \mathrm{~mm}$, i.e. a ratio of 1.3 , or 5 times greater than the controls. Glucose and lactate dehydrogenase ( $\mathrm{LDH}=\mathrm{EC}$ 1.1.1.27) movements into the oviduct fluid were unaffected by propionate addition.

Experiments were carried out to determine whether propionate could influence pyruvate appearance when supplied to the contraluminal membranes of the endosalpinx. The plasma volume of a $4 \mathrm{~kg}$ rabbit was assumed to be approximately $320 \mathrm{ml}$, and propionate sufficient to 
give an immediate plasma concentration of $10 \mathrm{mM}$ (i.e. $3200 \mu \mathrm{mol}$ ) was injected intravenously after a control period of $1 \frac{1}{2} \mathrm{~h}$. A further solution of propionate was then infused for the remainder of the experiment at a rate of $3200 \mu \mathrm{mol} / \mathrm{h}$. Plasma propionate was not measured in these experiments. As the data in Text-fig. 2 show, the effect on pyruvate appearance was as dramatic as that when propionate had been added to the lumen.

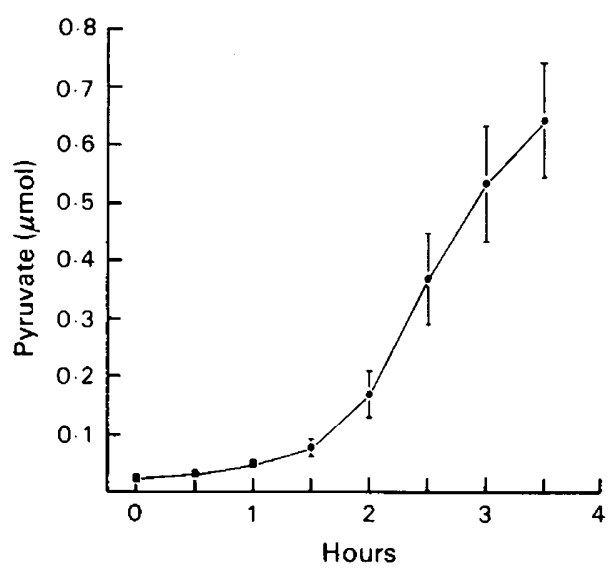

Text-fig. 2. The time course of pyruvate appearance in fluid circulating through the rabbit oviduct in vivo. Sodium propionate in an amount calculated to give a plasma concentration of 10 mM was infused intravenously after $1 \frac{1}{2} \mathrm{~h}$. Values are mean \pm s.e.m. for 5 oviducts.

$\alpha$-Cyano-4-hydroxycinnamate had no effect on the rate of pyruvate appearance when added at a concentration of $1 \mathrm{mM}$ to the medium perfusing the rabbit oviduct lumen in vivo, and when infused intravenously at this concentration, the animals died. Since pyruvate is an intermediate in the metabolic conversion of propionate into glucose, it was possible that the propionatestimulated pyruvate appearance could, to some extent, be a metabolic rather than a transport phenomenon. In order to examine this possibility, it was desirable to use an experimental system in which enhanced pyruvate efflux could be distinguished from a metabolic conversion, and such a situation was achieved by the use of oviduct tissue slices. The pyruvate content of unincubated slices was $0.029 \pm 0.005 \mu \mathrm{mol} / \mathrm{g}(n=4)$ and after $8 \mathrm{~min}$ incubation in vitro declined to very low levels which could not accurately be measured. By contrast, the pyruvate content of slices incubated for $8 \mathrm{~min}$ with $10 \mathrm{~mm}$-sodium propionate was $0.121 \pm 0.01 \mu \mathrm{mol} / \mathrm{g}(n=4)$ or 4 times the level in the unincubated controls.

\section{Discussion}

The rate of pyruvate appearance in the rabbit oviduct lumen is stimulated by $10 \mathrm{~mm}$-sodium pyruvate and similar results have been obtained with $1 \mathrm{~mm}$-sodium propionate.

One explanation for this phenomenon could be in terms of 'counter-transport' whereby the flux of a compound in a given direction may be stimulated by the movement of a second compound which shares the same carrier-mediated transport system. Such an interpretation readily accounts for the effect of propionate in inhibiting the entry and stimulating the efflux of pyruvate in isolated epithelial cells from the rat small intestine (Lamers \& Hülsmann, 1975). The difficulty with this explanation as applied to the rabbit oviduct is that propionate was equally effective whether applied to the lumen or to the vascular side of the tissue, and it would be unwise in the absence of further evidence to speculate on the molecular mechanism involved. The lack of inhibition of pyruvate appearance by $\alpha$-cyano-4-hydroxycinnamate suggests that a 
different pyruvate transporting system operates in the rabbit oviduct than in rat liver mitochondria or human erythrocytes.

An alternative explanation is that the rabbit oviduct can convert propionate into pyruvate, which is then secreted into the lumen. Strong support for this idea came from the experiments in which propionate was shown to increase the pyruvate content of the oviduct in a preparation completely isolated from the whole animal. The metabolic pathway from propionate to pyruvate proceeds via succinyl coA, oxaloacetate and phosphoenolpyruvate, and requires biotin and vitamin $B_{12}$. It is conceivable that propionate stimulates the conversion of some precursor into pyruvate, but this seems most unlikely. The extent to which any of the above possibilities contribute to the stimulation of pyruvate appearance in vivo could be checked by infusing radioactive propionate and measuring its specific activity, and that of the pyruvate appearing in the oviduct lumen, over a period of time.

The significance of the propionate stimulation of pyruvate appearance is in relation to recent work on the energy requirements of rabbit ova. Kane (1979) has shown that in addition to pyruvate, certain fatty acids, with the notable exception of arachidonic acid, can support the growth of fertilized 1-cell eggs to viable morulae. At concentrations of $10^{-3}$ and $10^{-4} \mathrm{M}$, propionic acid was as effective as pyruvate as an energy source for development to the morula stage, but only about half as effective in supporting the growth of morulae into early blastocysts. It would therefore be interesting to investigate the interactions between the movement of pyruvate, propionate and other short chain fatty acids (a) across the wall of the oviduct and (b) into unfertilized and fertilized eggs and (c) the extent to which these fatty acids can be converted into pyruvate.

I am grateful to the Medical Research Council and The Wellcome Trust for research grants.

\section{References}

Biggers, J.D. \& Stern, S. (1973) Metabolism of the preimplantation mammalian embryo. Adv. Reprod. Physiol. 6, 1-59.

Brackett, B.G. \& Mastroianni, L., Jr (1974) Composition of oviducal fluid. In The Oviduct and its Functions, pp. 133-150. Eds A. D. Johnson \& C. W. Foley. Academic Press, New York.

Bronk, J.R. \& Parsons, D.S. (1965) The polarographic determination of the respiration of the small intestine of the rat. Biochim. Biophys. Acta 107, 397-404.

Halestrap, A.P. \& Denton, R.M. (1974) Specific inhibition of pyruvate transport in rat liver mitochondria and human erythrocytes by $\alpha$-cyano-4hydroxycinnamate. Biochem. J. 138, 313-316.
Kane, M.T. (1979) Fatty acids as energy sources for culture of one-cell rabbit ova to viable morulae. Biol. Reprod. 20, 323-332.

Lamers, J.M.J. \& Hülsmann, W.C. (1975) Inhibition of pyruvate transport by fatty acids in isolated cells from rat small intestine. Biochim. Biophys. Acta 394, $31-45$.

Leese, H.J. \& Aldridge, S. (1979) The movement of pyruvate, lactate and lactate hydrogenase into rabbit oviductal fluid. J. Reprod. Fert. 56, 619-622.

Leese, H.J. \& Bronk, J.R. (1972) Automated fluorometric analysis of micromolar quantities of ATP, glucose and lactic acid. Analyt. Biochem. 45, 211-221. 